\title{
High primary resistance to metronidazole and levofloxacin, and a moderate resistance to clarithromycin in Helicobacter pylori isolated from Karnataka patients
}

\author{
Vignesh Shetty ${ }^{1}$, Binit Lamichhane ${ }^{2}$, Chin Yen Tay ${ }^{2,3}$, Ganesh C. Pai ${ }^{4}$, Ramachandra Lingadakai $^{5}$,
} Girisha Balaraju${ }^{4}$, Shiran Shetty ${ }^{4}$, Mamatha Ballal ${ }^{1 \dagger}$ and Eng Guan Chua ${ }^{2^{*+}}$ (1)

\begin{abstract}
Background: Due to increased prevalence of H. pylori antimicrobial resistance worldwide and more importantly the resistance patterns vary between different geographical regions, it is important to survey local $H$. pylori antibiotic resistance profile to provide physicians with more informed drug choices to better treat $H$. pylori infection. To our knowledge, this is the first study to examine the prevalence of antimicrobial resistance of H. pylori in Karnataka state of South India.

Results: A total of $113 \mathrm{H}$. pylori strains were isolated from gastric biopsies and tested: $81.4 \%$ were resistant to metronidazole, 54.9\% were resistant to levofloxacin, 20.4\% were resistant to clarithromycin, 5.3\% were resistant to tetracycline and $7.1 \%$ were resistant to amoxicillin. Multidrug resistance was detected in $59.3 \%$ of total isolated strains, among which $86.6 \%$ were resistant to at least both metronidazole and levofloxacin. In this study, 38 out of $113 \mathrm{H}$. pylori strains had been whole-genome sequenced. Based on the draft genomes, RdxA and/or FrxA inactivation mutations were found to present in 75\% of metronidazole-resistant strains. Clarithromycin-resistant strains had mainly A2143G and G2224A mutations in the 23 rRNA gene. While 87.1\% levofloxacin-resistant strains had amino acid substitution mutations occurring predominantly at N87 and D91 in GyrA, novel mutations in the same protein including an insertion of five amino acid residues (QDNSV), immediately after the start codon, and a substitution mutation at R295 were identified.
\end{abstract}

Conclusion: High primary resistance to metronidazole and levofloxacin, and a modest occurrence of clarithromycin resistance were revealed in $\mathrm{H}$. pylori strains isolated from Karnataka patients. Therefore metronidazole-, levofloxacinand clarithromycin-based triple therapies are not suitable as first-line treatment in Karnataka. Both amoxicillin and tetracycline can still be used to eradicate H. pylori infection in this region. We also revealed novel mutations in GyrA protein that possibly contribute to H. pylori resistance in levofloxacin, which merit further investigations.

Keywords: Helicobacter pylori, Antibiotic susceptibility, India, Agar dilution, Minimum inhibitory concentration

\footnotetext{
*Correspondence: eng.chua@uwa.edu.au

${ }^{\dagger}$ Mamatha Ballal and Eng Guan Chua are joint senior authors

${ }^{2}$ Marshall Centre for Infectious Diseases Research and Training, School

of Biomedical Sciences, University of Western Australia, Crawley, WA

Australia

Full list of author information is available at the end of the article
} 


\section{Introduction}

Helicobacter pylori is a gastric pathogen that colonises human stomach, leading to clinical manifestations of chronic gastritis, peptic ulcer disease, gastric adenocarcinoma and mucosa associated lymphoid tissue (MALT) lymphoma [1]. Current standard $H$. pylori eradication regime, also known as triple therapy, comprises two antibiotics (amoxicillin and clarithromycin or metronidazole) and a proton pump inhibitor (PPI) [5]. However, due to surging prevalence of clarithromycin and metronidazole resistance in $\mathrm{H}$. pylori, the treatment success rate of either clarithromycin-based or metronidazole-based triple therapy is merely $80 \%$ or less in certain global regions [2-6]. To improve H. pylori eradication rate, different treatment strategies have been implemented including concomitant, sequential and bismuth-based quadruple regimens, as well as the culture-based, susceptibilityguided treatment approach $[7,8]$.

While different antibiotics have been used for the treatment of $H$. pylori infection, the bacterium has developed several mechanisms to protect itself against the antimicrobial activities of levofloxacin, tetracycline and rifabutin, in addition to metronidazole and clarithromycin [9]. Metronidazole resistance is complex but is primarily due to the inactivation of $\mathrm{RdxA}$, an oxygen-insensitive NADPH nitroreductase [10]. Additionally, it has been demonstrated that the level of metronidazole resistance attributed to RdxA inactivation can be enhanced further by FrxA nitroreductase [11]. For clarithromycin resistance, substitution mutations involving the adenine residues at positions 2142 and 2143 were frequently detected in the $23 r R N A$ gene [12]. Furthermore, amino acid substitutions at positions 87 and 91 in DNA gyrase subunit A (GyrA) resulted in H. pylori resistance against fluroquinolones, whilst point mutations in $p b p 1$ and $16 S$ rRNA genes have been linked to amoxicillin and tetracycline resistance, respectively [13-15].

While high prevalence of metronidazole-resistant $H$. pylori isolates is common in several places in India like Kolkata, central Gujarat, Chandigarh, Delhi, Lucknow, Hyderabad and Chennai, the rates of $H$. pylori resistance to other antibiotics such as clarithromycin, ciprofloxacin, amoxicillin and tetracycline varied [16-18]. Since the antimicrobial resistance patterns of $H$. pylori vary between different geographical areas, it is vital to implement local antibiotic resistance surveillance program to provide physicians with more informed drug choices to effectively treat $H$. pylori-related gastric diseases. In India, regional antimicrobial resistance profile of $H$. pylori is generally lacking across the nation. Therefore, in this study, we aimed to examine the prevalence of $H$. pylori antibiotic resistance in Karnataka state of India, specifically against five antibiotics including metronidazole, clarithromycin, levofloxacin, tetracycline and amoxicillin. The findings of our work would provide a better understanding of the prevalence of drug-resistant $H$. pylori strains in Karnataka to facilitate the design of more rational and effective antibiotic combinations for eradication of $H$. pylori infection.

\section{Results}

From May 2014 to May 2017, 355 Karnataka patients underwent endoscopy at Kastruba Medical College and Tertiary Care Hospital, among which 180 (50.7\%) were positive for $H$. pylori infection based on histopathology examination. A total of $113 \mathrm{H}$. pylori strains were successfully isolated, 80 (70.8\%) from male and $33(29.2 \%)$ from female patients. The average age was $46.2 \pm 14$ years old. Among 113 culture-positive patients recruited from nine districts in Karnataka state, two-third were from Udupi (31.9\%, 36/113), Davangere (19.5\%, 22/113) and Shimoga $(15.9 \%, 18 / 113)$, and the rest were from Bellary $(4.4 \%, 5 / 113)$, Chikmagalur $(5.3 \%, 6 / 113)$, Chitradurga $(10.6 \%, 12 / 113)$, Hassan $(0.9 \%, 1 / 113)$, Haveri $(4.4 \%$, 5/113) and Uttar Kannada (7.1\%, 8/113). Endoscopic examinations further diagnosed 78 (69\%), 30 (26.6\%) and $5(4.4 \%)$ patients with gastritis, peptic ulcer disease and intestinal metaplasia, respectively. We next examined the susceptibility of each $H$. pylori strain against five different antibiotics including metronidazole, clarithromycin, levofloxacin, tetracycline and amoxicillin. The demographic data of patients and the MIC values for all strains are provided in Additional file 1.

Overall, $14.2 \%$ (16/113) strains were susceptible to all antibiotics used in this study (Table 1). Notably, $81.4 \%$ $(92 / 113)$ of isolated strains were resistant to metronidazole. We also observed a high levofloxacin resistance rate among our strains $(54.9 \%, 62 / 113)$. Resistance rates towards clarithromycin, tetracycline and amoxicillin were $20.4 \%(23 / 113), 5.3 \%(6 / 113)$ and $7.1 \%(8 / 113)$, respectively. Of 67 strains $(59.3 \%, 67 / 113)$ that were multidrug-resistant, $58(86.6 \%, 58 / 67)$ were resistant to at least both metronidazole and levofloxacin. While there was no association between patient ages and the metronidazole resistance rate of isolated clinical strains, metronidazole resistance was moderately lower in females than males $(P=0.06)$ (Table 2). Additionally, resistance to levofloxacin appeared to be the highest in patients aged 60 years and above.

Of 113 strains included in this study, 38 had been sequenced at whole-genome level and reported in our earlier work [19]. Inactivation of $\mathrm{RdxA}$ and/or FrxA, nucleotide substitutions in $23 S$ rRNA gene and amino acid substitutions in GyrA protein, conferring metronidazole, clarithromycin and levofloxacin resistance, respectively, were examined in these 38 strains to 
Table 1 Antibiotic resistance rates of $113 \mathrm{H}$. pylori strains isolated in this study

\begin{tabular}{lc}
\hline Resistance & Total (\%) \\
\hline Overall & \\
MET & $92(81.4)$ \\
CLA & $23(20.4)$ \\
LEV & $62(54.9)$ \\
TET & $6(5.3)$ \\
AMO & $8(7.1)$ \\
No resistance & $16(14.2)$ \\
Single resistance & $30(26.5)$ \\
MET & $25(22.1)$ \\
CLA & $1(0.9)$ \\
LEV & $4(3.5)$ \\
Dual resistance & $42(37.2)$ \\
MET + LEV & $36(31.9)$ \\
MET + CLA & $6(5.3)$ \\
Triple resistance & $23(20.4)$ \\
MET+ CLA + LEV & $13(11.5)$ \\
MET+ CLA + AMO & $1(0.9)$ \\
MET+ LEV + AMO & $5(4.4)$ \\
MET+ LEV + TET & $2(1.8)$ \\
MET + AMO + TET & $2(1.8)$ \\
Quadruple resistance & $2(1.8)$ \\
MET + CLA + LEVO+TET & $2(1.8)$ \\
\hline
\end{tabular}

MET: Metronidazole; CLA: clarithromycin; LEV: levofloxacin; TET: tetracycline; AMO: amoxicillin

determine any of these mutations, if present, matches the susceptibility results. Among 36 sequenced metronidazole-resistant strains, 27 were expected to express non-functional or altered $\mathrm{RdxA}$ and/or FrxA proteins resulting from nonsense or frameshift mutations in the coding sequences, and partial gene deletions which would have been likely through recombination (Table 3). In the remaining metronidazole-resistant strains, as well as two metronidazole-susceptible strains, both genes were intact.
Mutations in the 23 rRNA gene were detected in all nine clarithromycin-resistant sequenced strains, predominantly A2143G and G2224A single mutations (Table 4). One strain contained double mutations of A2142G and G2224A in its 23 rRNA gene. Out of 31 levofloxacin-resistant strains, 18 (58.1\%) had amino acid substitution occurred at D91 in GyrA, eight (25.8\%) at N87 and one at both positions (Table 5). We also noticed that two strains exhibited an unprecedented $\mathrm{N}$-terminal extension of GyrA by five amino acid residues (QDNSV), immediately after the start codon, and one showed a mutation at R295.

\section{Discussion}

To our knowledge, this is the first study to examine the prevalence of antimicrobial resistance of $H$. pylori in Karnataka state of South India. In India, the prevalence of metronidazole-resistant $H$. pylori is remarkably high, with resistance rates reaching at least $80 \%$ in several areas $[16-18,20,21]$. Importantly, such high occurrence of metronidazole resistance was also observed in our isolated clinical strains, indicating that conventional triple therapy consisting of metronidazole should not be used to treat $H$. pylori infection in Karnataka. While the main mechanisms conferring $H$. pylori with metronidazole resistance involving RdxA and/or FrxA inactivation mutations were present in $75 \%$ of our sequenced metronidazole-resistant strains, in the remaining strains there were considerable number of missense mutations especially in $r d x A$ gene that we cannot possibly rule out their role in metronidazole resistance by inducing protein conformational changes and hence dampening the reduction-activation activity of $\mathrm{RdxA}$ towards metronidazole [11, 22, 23].

In Maastricht V/Florence consensus report, it was recommended that clarithromycin-based triple therapy should be avoided if local clarithromycin resistance rate exceeds $15 \%$ [24]. As the primary clarithromycin resistance rate in Karnataka was $20.4 \%$, which is above the

Table 2 Antimicrobial resistance according to gender and age distributions

\begin{tabular}{|c|c|c|c|c|c|c|c|}
\hline \multirow{2}{*}{$\begin{array}{l}\text { Antibiotic } \\
\text { resistance }\end{array}$} & \multicolumn{2}{|l|}{ Gender } & \multirow[t]{2}{*}{$P$} & \multicolumn{3}{|c|}{ Age group } & \multirow[t]{2}{*}{$P$} \\
\hline & $\begin{array}{l}\text { Female } \\
(n=33)\end{array}$ & $\begin{array}{l}\text { Male } \\
(n=80)\end{array}$ & & $\begin{array}{l}20-39 \\
(n=41)\end{array}$ & $\begin{array}{l}40-59 \\
(n=48)\end{array}$ & $\begin{array}{l}60 \text { and above } \\
(n=24)\end{array}$ & \\
\hline MET & $23(69.7)$ & 69 (86.3) & 0.06 & $32(78)$ & $42(87.5)$ & $18(75)$ & 0.32 \\
\hline CLA & $8(24.2)$ & 15 (18.8) & 0.61 & $5(12.2)$ & $12(25)$ & $6(25)$ & 0.29 \\
\hline LEV & $18(54.5)$ & $44(55)$ & 1 & $24(58.5)$ & $21(43.8)$ & $17(70.8)$ & 0.08 \\
\hline AMO & $1(3)$ & $7(8.8)$ & 0.43 & $1(2.4)$ & $5(10.4)$ & $2(8.3)$ & 0.33 \\
\hline TET & $1(3)$ & $5(6.3)$ & 0.67 & $1(2.4)$ & $2(4.2)$ & $3(12.5)$ & 0.21 \\
\hline
\end{tabular}

MET: Metronidazole; CLA: clarithromycin; LEV: levofloxacin; TET: tetracycline; AMO: amoxicillin 
Table 3 Inactivation mutations in $r d x A$ and frxA genes in sequenced metronidazole-resistant $H$. pylori strains

\begin{tabular}{|c|c|c|c|}
\hline Strain & MIC $(\mu \mathrm{g} / \mathrm{ml})$ & $\begin{array}{l}r d x A \\
\text { Mutation type (position) }\end{array}$ & $\begin{array}{l}\text { frxA } \\
\text { Mutation type (position) }\end{array}$ \\
\hline KH1 & 64 & Nonsense (65) & - \\
\hline $\mathrm{KH} 2$ & 64 & - & - \\
\hline KH3 & 64 & Nonsense (50) & Nonsense (199) \\
\hline KH4 & 16 & Nonsense (50) & - \\
\hline KH6 & 64 & - & Frameshift (70) \\
\hline KH7 & 64 & - & Nonsense (68) \\
\hline KH8 & 64 & Frameshift (136) & Frameshift (18) \\
\hline KH9 & 32 & - & Deletion of 58 bp C-terminal region \\
\hline KH11 & 64 & - & - \\
\hline KH12 & 64 & Frameshift (65) & Deletion of 303 bp N-terminal region \\
\hline KH13 & 64 & - & Frameshift (18) \\
\hline KH14 & 64 & - & Nonsense (141) \\
\hline KH15 & 64 & - & - \\
\hline KH16 & 64 & - & - \\
\hline KH17 & 64 & Nonsense (50) & - \\
\hline KH18 & 64 & Fragmented & - \\
\hline KH19 & 64 & - & Frameshift (44) \\
\hline $\mathrm{KH} 2 \mathrm{O}$ & 64 & - & - \\
\hline $\mathrm{KH} 21$ & 64 & Nonsense (50) & Frameshift (70) \\
\hline $\mathrm{KH} 22$ & 32 & Nonsense (50) & - \\
\hline $\mathrm{KH} 23$ & 32 & - & Frameshift (154) \\
\hline $\mathrm{KH} 25$ & 64 & - & Frameshift (18) \\
\hline KH26 & 64 & - & Nonsense (68) \\
\hline $\mathrm{KH} 27$ & 64 & - & - \\
\hline $\mathrm{KH} 28$ & 64 & Frameshift (98) & Frameshift (18) \\
\hline KH29 & 64 & - & - \\
\hline KH30 & 64 & Frameshift (185) & Nonsense (86) \\
\hline KH32 & 16 & - & - \\
\hline KH33 & 64 & - & Frameshift (18) \\
\hline KH36 & 32 & Frameshift (161) & - \\
\hline KH37 & 64 & Nonsense (65) & - \\
\hline KH38 & 64 & Nonsense (50) & Frameshift (18) \\
\hline KH41 & 64 & - & 268 bp insertion \\
\hline KH43 & 64 & Frameshift (72) & Nonsense (176) \\
\hline KH44 & 64 & - & - \\
\hline KH45 & 64 & - & Frameshift (106) \\
\hline
\end{tabular}

$15 \%$ limit, suggesting that clarithromycin-based triple therapy is also not an appropriate option for the treatment of $H$. pylori infection in Karnataka. Resistance to clarithromycin is generally associated with point mutations in the $23 S$ rRNA gene particularly at positions 2142 and 2143 [25]. In this study, the predominant mutations were A2143G and G2224A, where the latter has been linked to $H$. pylori clarithromycin resistance in the northeast part of China [26].

In tandem with a remarkably high prevalence of metronidazole resistance and a moderate occurrence of clarithromycin resistance, more than half of our isolated $H$. pylori strains were also resistant to levofloxacin, in agreement with prior reports of high levofloxacin resistance rates in several developing nations including Nepal, Vietnam and Bangladesh [27-29]. Levofloxacin resistance in $H$. pylori is acquired primarily by amino acid substitution mutations in GyrA protein involving N87 and D91 [30]. Similarly, 87.1\% (27/31) of our sequenced levofloxacin-resistant strains were found to harbour these frequently reported mutations. Of four remaining strains, interestingly, two contained an insertion of 
Table 4 23S rRNA gene mutations in nine sequenced clarithromycin-resistant $H$. pylori strains

\begin{tabular}{lll}
\hline Strain & MIC $(\boldsymbol{\mu g} / \mathbf{m l})$ & Mutation(s) \\
\hline KH6 & 1 & A2143G \\
KH16 & 1 & A2143G \\
KH19 & 1 & A2143G \\
KH20 & 1 & G2224A \\
KH21 & 1 & G2224A \\
KH29 & 1 & A2143G \\
KH35 & 1 & G2224A \\
$K H 36$ & 1 & A2142G, G2224A \\
KH41 & 1 & G2224A \\
\hline
\end{tabular}

Table 5 GyrA mutations in sequenced levofloxacinresistant $\boldsymbol{H}$. pylori strains

\begin{tabular}{|c|c|c|}
\hline Strain & MIC $(\mu \mathrm{g} / \mathrm{ml})$ & Mutation(s) \\
\hline KH1 & 4 & D91N, N87K \\
\hline $\mathrm{KH} 2$ & 4 & $\mathrm{R} 295 \mathrm{H}$ \\
\hline $\mathrm{KH} 3$ & 4 & D91N \\
\hline KH6 & 4 & D91G \\
\hline KH8 & 4 & D91N \\
\hline KH9 & 4 & D91N \\
\hline KH12 & 2 & D91N \\
\hline KH13 & 4 & D91N \\
\hline KH14 & 4 & N871 \\
\hline KH15 & 4 & D91G \\
\hline KH16 & 4 & - \\
\hline KH17 & 4 & D91G \\
\hline KH18 & 4 & N87K \\
\hline KH19 & 4 & D91N \\
\hline KH2O & 4 & 5-amino-acid $\mathrm{N}$-terminal extension \\
\hline KH21 & 4 & D91N \\
\hline KH25 & 4 & D91Y \\
\hline KH26 & 4 & N87K \\
\hline KH27 & 4 & D91Y \\
\hline $\mathrm{KH} 28$ & 4 & D91Y \\
\hline KH30 & 4 & D91N \\
\hline KH32 & 4 & D91G \\
\hline KH33 & 4 & D91N \\
\hline KH36 & 4 & N87K \\
\hline KH37 & 4 & D91N \\
\hline KH38 & 4 & N87K \\
\hline KH40 & 4 & 5-amino-acid $\mathrm{N}$-terminal extension \\
\hline KH41 & 4 & N87K \\
\hline KH43 & 4 & D91N \\
\hline KH44 & 4 & N87K \\
\hline KH45 & 4 & N87K \\
\hline
\end{tabular}

QDNSV residues next to the start codon in their GyrA protein. It is highly likely that this five-amino-acid insertion would induce conformational changes in GyrA protein, reducing its binding affinity to fluoroquinolones and thus rendering levofloxacin ineffective. Further, we found one strain that had a R295H mutation in GyrA. Further mutagenesis study would be of interest to confirm the role of these novel GyrA mutations in $H$. pylori resistance to fluoroquinolones including levofloxacin.

Bearing in mind the high to modest rates of $H$. pylori resistance to metronidazole, levofloxacin and clarithromycin in this study, the use of triple therapy containing either combination of these drugs will likely result in treatment failure and should therefore be avoided. Our findings also suggest that triple therapy containing amoxicillin, tetracycline and PPI can be used as one of the first-line regimens for treating H. pylori infection in Karnataka. In a recent study conducted in Shanghai, China, where $H$. pylori metronidazole and clarithromycin resistance rates were $74.2 \%$ and $24.2 \%$, respectively, at similar levels to Karnataka, the use of quadruple therapy containing bismuth, high-dose metronidazole to overcome existing resistance, clarithromycin and PPI had high modified intention-to-treat (ITT) and per-protocol (PP) cure rates of $90.3 \%$ and $96 \%$, respectively [31]. In another study conducted in Zhejiang, China, where $H$. pylori clarithromycin resistance is prevalent, bismuth-based quadruple therapy containing amoxicillin and clarithromycin was shown to achieve both ITT and PP eradication rates of 86.1 and $92.3 \%$, respectively [32]. Hence, it is worth examining the use and the effects of the abovementioned bismuth-based quadruple therapies for the treatment of $H$. pylori infection in Karnataka population. If proven effective, local medical professionals would be able to continue using both relatively inexpensive metronidazole and clarithromycin drugs as part of $H$. pylori eradication regimens in Karnataka.

\section{Conclusions}

In our study, high resistance rates of metronidazole and levofloxacin resistance, and a modest occurrence of clarithromycin resistance were revealed in $H$. pylori strains isolated from patients in Karnataka, providing important information that triple therapies based on these drugs are not useful as first-line treatment in this South India region. Both amoxicillin and tetracycline are still useful for eradicating $H$. pylori infection in Karnataka. We also revealed novel mutations in GyrA protein that possibly contribute to $H$. pylori resistance in levofloxacin, which merit further investigations. 


\section{Methods}

\section{Gastric biopsies collection}

This study was approved by the Manipal University Human Ethics Committee (Ref. No. IEC301/2014). Gastric biopsies were obtained for both histopathological examination and $H$. pylori culturing with informed and written consent from dyspeptic patients who underwent endoscopy at Kastruba Medical College and Tertiary Care Hospital, Manipal (KMC) from May 2014 to May 2017. In total, $113 \mathrm{H}$. pylori clinical strains were successfully isolated from patients who lived in Karnataka state of South India, had not previously received any $\mathrm{H}_{2}$ receptor blocker, PPI or nonsteroidal anti-inflammatory drug (NSAID) medication, and without any history of gastric surgery and $H$. pylori eradication treatment, were recruited. Four biopsy specimens (two each from antrum and corpus) were collected in Bouin's fluid for histopathological examination. Two additional specimens (one each from antrum and corpus) were collected in transport medium for bacterial isolation.

\section{Bacterial culturing}

Transport medium containing biopsy specimens was vortexed prior to plating $100 \mu \mathrm{l}$ of the solution on brain heart infusion agar (BHIA) supplemented with 5\% (vol/ vol) horse serum (Gibco, New Zealand), 0.5\% (vol/vol) BBL IsoVitaleX enrichment medium (Becton, Dickinson and Company, USA), trimethoprim $(5 \mu \mathrm{g} / \mathrm{ml})$ and vancomycin $(6 \mu \mathrm{g} / \mathrm{ml})$ (HiMedia Ltd., India). The plates were then incubated in a microaerobic atmosphere $\left(5 \% \mathrm{O}_{2}\right.$, $10 \% \mathrm{CO}_{2}$ and $85 \% \mathrm{~N}_{2}$ ) at $37{ }^{\circ} \mathrm{C}$ for a period of 3 to 7 days. Successful $H$. pylori isolate was identified based on its distinctive colony morphology, appearance of Gramnegative bacillus under the microscope, positive urease, oxidase and catalase reactions, and PCR detection of $H$. pylori-specific glmM gene.

\section{Minimum inhibitory concentration (MIC) determination using agar dilution method}

Plates were prepared containing 5\% (vol/vol) horse serum and serial two-fold dilutions of each antibiotic. The range of final concentrations for each antibiotic were 2-64 $\mu \mathrm{g}$ / $\mathrm{ml}$ for metronidazole, $0.125-1 \mu \mathrm{g} / \mathrm{ml}$ for clarithromycin, $0.25-1 \mu \mathrm{g} / \mathrm{ml}$ for amoxicillin, and $1-4 \mu \mathrm{g} / \mathrm{ml}$ for both levofloxacin and tetracycline. Bacterial suspension with turbidity of 2.0 McFarland standard was prepared from a 24-h old culture plate in saline. Two $\mu \mathrm{l}$ of bacterial suspension was inoculated onto each antibiotic plate, followed by incubation in a microaerobic atmosphere at $37{ }^{\circ} \mathrm{C}$ for 3 days. The MIC was then determined at the lowest antibiotic concentration where bacterial growth was completely inhibited. According to the guidelines of European Committee on Antimicrobial Susceptibility
Testing (EUCAST), bacterial isolates are considered to be antibiotic-resistant if the MIC value is $>8 \mu \mathrm{g} / \mathrm{ml}$ for metronidazole, $>0.5 \mu \mathrm{g} / \mathrm{ml}$ for clarithromycin, $>0.12 \mu \mathrm{g} / \mathrm{ml}$ for amoxicillin, and $>1 \mu \mathrm{g} / \mathrm{ml}$ for both tetracycline and levofloxacin.

\section{Mutation analysis}

Thirty-eight draft genomes were annotated using Prokka v1.12 [33]. The Prokka-annotated draft genomes are available at the public data repository Figshare (https:// figshare.com/), with https://doi.org/10.6084/m9.figsh are.8016128. To obtain $r d x A$, frxA, 23S rRNA and $g y r A$ nucleotide sequences from each strain, blastn search of hp0954, hp0642, hpr01 and hp0701, respectively, from $H$. pylori 26695 reference genome was performed on CLC Genomic Workbench 11 (Qiagen, Germany). Extracted $r d x A, f r x A$ and $g y r A$ genes were translated into amino acid sequences prior to alignment. For extracted $23 S$ $r R N A$ genes, sequence alignment was performed at the nucleotide level. Aligned sequences were then compared between resistant and sensitive strains, with reference sequence included, to examine for reported and novel mutations.

\section{Statistical analysis}

For statistical analysis, Fisher's exact test and Fisher-Freeman-Halton's test were used, as appropriate. Only $p$ value of $<0.05$ was considered statistically significant.

\section{Additional file}

Additional file 1. Patient demographics and MIC values. This file contains the minimum inhibitory concentrations of all tested $\mathrm{H}$. pylori clinical strains and the demographic characteristics of patients recruited in this study.

\section{Acknowledgements \\ None.}

\section{Authors' contributions}

Bacterial culturing, collection of clinical data and antibiotic susceptibility testing: VS; Preparation of manuscript: EGC, BL and VS; Data analysis: EGC, BL and VS; Design and conceptualisation of study: MB, EGC and CYT; Endoscopy examination and collection of gastric biopsy specimens: GCP, RL, GB and SS; Funding and reagents: MB and CYT. All authors read and approved the final manuscript.

\section{Funding}

This project was supported by Shenzhen's Sanming Project (Grant No: SZSM201510050), National Health and Medical Research Council (Grant No. 572723) and the Vice Chancellor of the University of Western Australia.

\section{Availability of data and materials}

Data are available upon request from the corresponding author (EGC).

\section{Ethics approval and consent to participate}

This study was approved by the Manipal University Human Ethics Committee (Ref. No. IEC301/2014). Informed and written consent were obtained from 
dyspeptic patients who underwent endoscopy at Kastruba Medical College and Tertiary Care Hospital, Manipal (KMC) from May 2014 to May 2017.

\section{Consent for publication}

Not applicable.

\section{Competing interests}

The authors declare that they have no competing interests.

\begin{abstract}
Author details
1 Enteric Diseases Division, Central Research Lab, Kasturba Medical College, Manipal Academy of Higher Education, Manipal, India. ${ }^{2}$ Marshall Centre for Infectious Diseases Research and Training, School of Biomedical Sciences, University of Western Australia, Crawley, WA, Australia. ${ }^{3}$ Shenzhen Dapeng New District Kuichong People Hospital, Shenzhen City, Guangdong Province, China. ${ }^{4}$ Department of Gastroenterology \& Hepatology, Kasturba Medical College, Manipal Academy of Higher Education, Manipal, Karnataka, India. ${ }^{5}$ Department of Surgery, Kasturba Medical College, Manipal Academy of Higher Education, Manipal, Karnataka, India.
\end{abstract}

Received: 6 March 2019 Accepted: 2 May 2019

Published online: 13 May 2019

\section{References}

1. Kusters JG, van Vliet AHM, Kuipers EJ. Pathogenesis of Helicobacter pylori infection. Clin Microbiol Rev. 2006;19(3):449-90.

2. Iwanczak BM, Borys-Iwanicka A, Biernat M, Gosciniak G. Assessment of sequential and standard triple therapy in treatment of Helicobacter pylori infection in children dependent on bacteria sensitivity to antibiotics. Adv Clin Exp Med. 2016;25(4):701-8.

3. Pellicano R, Palmas F, Ponzetto A, Astegiano M, Smedile A, Morgando $A$, et al. Decreasing eradicaton rate of Helicobacter pylori infection with metronidazole-based triple therapy. A randomised study. Minerva Gastroenterol Dietol. 2002;48(3):265-70.

4. Kabakambira JD, Hategeka C, Page C, Ntirenganya C, Dusabejambo $\checkmark$, Ndoli J, et al. Efficacy of Helicobacter pylori eradication regimens in Rwanda: a randomized controlled trial. BMC Gastroenterol. 2018;18(1):134.

5. Cheha KM, Dib SOA, Alhalabi MM. Pilot study: comparing efficacy of 14-day triple therapy Clarithromycin versus levofloxacin on eradication of Helicobacter pylori infection in Syrian population single-center experience. Avicenna J Med. 2018;8(1):14-7.

6. Mabe K, Okuda M, Kikuchi S, Amagai K, Yoshimura R, Kato M, et al. Randomized controlled trial: PPI-based triple therapy containing metronidazole versus clarithromycin as first-line treatment for Helicobacter pylori in adolescents and young adults in Japan. J Infect Chemother. 2018;24(7):538-43.

7. Lee JW, Kim N, Nam RH, Lee SM, Kwon YH, Sohn SD, et al. Favorable outcomes of culture-based Helicobacter pylori eradication therapy in a region with high antimicrobial resistance. Helicobacter. 2019;24:e12561.

8. Yeo YH, Hsu CC, Lee CC, Ho HJ, Lin JT, Wu MS, et al. Systematic review and network meta-analysis: comparative effectiveness of therapies for second-line Helicobacter pylori eradication. J Gastroenterol Hepatol. 2019;34(1):59-67.

9. Hu Y, Zhu Y, Lu NH. Novel and effective therapeutic regimens for Helicobacter pylori in an era of increasing antibiotic resistance. Front Cell Infect Microbiol. 2017;7:168.

10. Goodwin A, Kersulyte D, Sisson G, Veldhuyzen van Zanten SJ, Berg DE, Hoffman PS. Metronidazole resistance in Helicobacter pylori is due to null mutations in a gene ( $\mathrm{d} d x \mathrm{~A})$ that encodes an oxygen-insensitive NADPH nitroreductase. Mol Microbiol. 1998;28(2):383-93.

11. Jeong JY, Mukhopadhyay AK, Dailidiene D, Wang Y, Velapatino B, Gilman $\mathrm{RH}$, et al. Sequential inactivation of rdxA (HP0954) and frxA (HP0642) nitroreductase genes causes moderate and highlevel metronidazole resistance in Helicobacter pylori. J Bacteriol. 2000;182(18):5082-90.
12. De Francesco V, Zullo A, Hassan C, Giorgio F, Rosania R, lerardi E. Mechanisms of Helicobacter pylori antibiotic resistance: an updated appraisal. World J Gastrointest Pathophysiol. 2011;2(3):35.

13. Gerrits MM, de Zoete MR, Arents NL, Kuipers EJ, Kusters JG. $16 S$ rRNA mutation-mediated tetracycline resistance in Helicobacter pylori. Antimicrob Agents Chemother. 2002;46(9):2996-3000.

14. Rimbara E, Noguchi N, Kawai T, Sasatsu M. Mutations in penicillinbinding proteins 1, 2 and 3 are responsible for amoxicillin resistance in Helicobacter pylori. J Antimicrob Chemother. 2008;61(5):995-8.

15. Cattoir V, Nectoux J, Lascols C, Deforges L, Delchier JC, Megraud F, et al. Update on fluoroquinolone resistance in Helicobacter pylori: new mutations leading to resistance and first description of a gyrA polymorphism associated with hypersusceptibility. Int J Antimicrob Agents. 2007;29(4):389-96.

16. Pandya HB, Agravat HH, Patel JS, Sodagar NR. Emerging antimicrobial resistance pattern of Helicobacter pylori in central Gujarat. Indian J Med Microbiol. 2014;32(4):408-13.

17. Datta S, Chattopadhyay S, Patra R, De R, Ramamurthy T, Hembram J, et al. Most Helicobacter pylori strains of Kolkata in India are resistant to metronidazole but susceptible to other drugs commonly used for eradication and ulcer therapy. Aliment Pharmacol Ther. 2005;22(1):51-7.

18. Thyagarajan SP, Ray P, Das BK, Ayyagari A, Khan AA, Dharmalingam S, et al. Geographical difference in antimicrobial resistance pattern of Helicobacter pylori clinical isolates from Indian patients: multicentric study. J Gastroenterol Hepatol. 2003;18(12):1373-8.

19. Shetty V, Lamichhane B, Chua E-G, Ballal M, Tay C-Y. Draft genome sequences of 42 Helicobacter pylori isolates from rural regions of South India. Genome Announc. 2018;6(5):e01486-17.

20. Wani FA, Bashir G, Khan MA, Zargar SA, Rasool Z, Qadri Q. Antibiotic resistance in Helicobacter pylori: a mutational analysis from a tertiary care hospital in Kashmir, India. Indian J Med Microbiol. 2018;36(2):265-72.

21. Singh V, Mishra S, Maurya P, Rao G, Jain AK, Dixit VK, et al. Drug resistance pattern and clonality in H. pylori strains. J Infect Dev Ctries. 2009;3(2):130-6.

22. Gerrits MM, Van der Wouden E-J, Bax DA, Van Zwet AA, Van Vliet AHM, de Jong $A$, et al. Role of the rdxA and frxA genes in oxygen-dependent metronidazole resistance of Helicobacter pylori. J Med Microbiol. 2004;53(11):1123-8.

23. Martinez-Julvez M, Rojas AL, Olekhnovich I, Espinosa Angarica V, Hoffman PS, Sancho J. Structure of RdxA-an oxygen-insensitive nitroreductase essential for metronidazole activation in Helicobacter pylori. FEBS J. 2012;279(23):4306-17.

24. Malfertheiner P, Megraud F, O'Morain CA, Gisbert JP, Kuipers EJ, Axon AT, et al. Management of Helicobacter pylori infection-the Maastricht V/Florence consensus report. Gut. 2017;66(1):6-30.

25. Chen D, Cunningham SA, Cole NC, Kohner PC, Mandrekar JN, Patel R. Phenotypic and molecular antimicrobial susceptibility of Helicobacter pylori. Antimicrob Agents Chemother. 2017;61(4):e02530-16.

26. Hao Q, Li Y, Zhang Z-J, Liu Y, Gao H. New mutation points in 23 S rRNA gene associated with Helicobacter pylori resistance to clarithromycin in northeast China. World J Gastroenterol. 2004;10(7):1075.

27. Miftahussurur M, Shrestha PK, Subsomwong P, Sharma RP, Yamaoka Y. Emerging Helicobacter pylori levofloxacin resistance and novel genetic mutation in Nepal. BMC Microbiol. 2016;16(1):256.

28. Phan TN, Santona A, Tran VH, Tran TNH, Cappuccinelli P, Rubino S, et al. High rate of levofloxacin resistance in a background of clarithromycinand metronidazole-resistant Helicobacter pylori in Vietnam. Int J Antimicrob Agents. 2015;45(3):244-8.

29. Aftab H, Miftahussurur M, Subsomwong P, Ahmed F, Khan AK, Yamaoka Y. Helicobacter pylori antibiotic susceptibility patterns in Bangladesh: emerging levofloxacin resistance. J Infect Dev Ctries. 2016;10(3):245-53.

30. Hu Y, Zhang M, Lu B, Dai J. Helicobacter pylori and antibiotic resistance, a continuing and intractable problem. Helicobacter. 2016;21(5):349-63.

31. Long X, Chen Q, Yu L, Liang X, Liu W, Lu H. Bismuth improves efficacy of proton-pump inhibitor clarithromycin, metronidazole triple Helicobacter pylori therapy despite a high prevalence of antimicrobial resistance. Helicobacter. 2018;23(3):e12485. 
32. Wang L, Lin Z, Chen S, Li J, Chen C, Huang Z, et al. Ten-day bismuthcontaining quadruple therapy is effective as first-line therapy for Helicobacter pylori-related chronic gastritis: a prospective randomized study in China. Clin Microbiol Infect. 2017;23(6):391-5.

33. Seemann T. Prokka: rapid prokaryotic genome annotation. Bioinformatics. 2014;30(14):2068-9.

\section{Publisher's Note}

Springer Nature remains neutral with regard to jurisdictional claims in published maps and institutional affiliations.
Ready to submit your research? Choose BMC and benefit from:

- fast, convenient online submission

- thorough peer review by experienced researchers in your field

- rapid publication on acceptance

- support for research data, including large and complex data types

- gold Open Access which fosters wider collaboration and increased citations

- maximum visibility for your research: over $100 \mathrm{M}$ website views per year

At BMC, research is always in progress.

Learn more biomedcentral.com/submissions 